\title{
Study on Self-improvement Mechanism of College English and Information Technology Integration
}

\author{
Fan Zhenying ${ }^{1, a}$ \\ ${ }^{1}$ Department of Xingtai Medical College,Xingtai,Hebei,054000,China \\ a21304252@qq.com
}

Keywords: information technology; English; self-improvement; integration

\begin{abstract}
CSE of questionnaire on teachers, TISA etc, it explores relations between self-efficiency and information and technology integration conception of teacher computer in foreign language education institute of university. The results find that computer self-efficiency perception of college English teachers has medium and obvious correlated relations in statistics with their technology integration. While teaching experience of teachers and week number of profession development have no correlation to self-efficiency.
\end{abstract}

\section{Introduction}

With the approaching of information times, information technology represented by computer and internet is universally applied in every education field [1,2], information technology has become to be the necessary part in college class, it can be used to renew teaching methods and promote mutual-interaction of teachers and students. The class interaction supported by information technology has broken through the limitations that traditional teaching can not obtain visualization and intuition, it organically combines with technology such as text, image, video, cartoon and sound etc, so that it changes the interaction behavior[4] of teachers and students in class. TPACK is one set of professional knowledge system conforms to class requirement of teachers and students in information technology times, the scholars in every country have developed plenty of research work $[3,4]$ in recent years. With the deepening of research, more and more scholars find that TPACK is one kind of new knowledge involves with multiple conditions and factors, the master and application on this kind of knowledge by teachers are usually coordinated and functioned with many external factors. Therefore, how to define influence factors on English subject teaching knowledge of integration technology as well as subject knowledge constitute of coordinated relations between influence factors and integration technology have become to the important breakthrough point in this research.

This paper uses English class of college as example to explore how class interaction is implemented under support of information technology, it also analyzes the problems met during class interaction and relevant factors of affecting teaching interaction behavior of college English, so that it can provide reference for teacher to consult and use. It adopts a series of CSE, TISA etc to explore relations between self-efficiency of teacher computer and information technology integration perception of foreign language Education College in Liaocheng University. The computer self-efficiency perception of teachers are naturally the subjective experience of teachers, so the application of self-report questionnaire easily has subjective tendency and it has inconformity to class teaching behavior in reality.

\section{Self-efficiency of college English under information technology}

With the promotion of information technology, its integration with college English class has become to be the hot point for research. But in the reform process of college English teaching, teachers are still unknown to instruction theory of reform: integration of information technology and English class of college, so that it causes shortage of theory instruction in the integration process. We should combine information technology and course integration theory with foreign language teaching theory, and use it as instruction, rely on information technology method to develop the 
organic-combination teaching and learning activity of self-autonomy, research and cooperation of by using teachers as major, students as main body, integrating information technology, information resources and information method with English course of college, which forms college English teaching process of by teaching structure of combing with leading and main body. The main leading effect of teachers is to display organization and research instruction and strategy design of self-learning in context creation, provision of information resources and cooperative learning etc. In this process, the learning way of students must change from traditional reception learning to initiative learning, self-learning and research learning. Teachers should apply teaching design idea of emphasizing teaching and learning to make teaching design, cultivate the solid abilities of students in listening, speaking, reading and writing, and cultivate the innovative talents with creative thinking on this basis.

The access lacking of technology is one of external barrier to affect integration between information technology and course. However, even if they can obtain technology, if they want to produce effect on teaching, they must apply education technology in the practice. In fact, the equipment of obtaining and using information technology is just necessary condition, while effective integration needs teachers to fully master application technology in the class. When technology can be obtained, internal barrier restricts integration of information technology and course.

\section{Effect of computer self-efficiency}

As it is indicated by diagram 1, it is the influence range on key cause and variable of computer self-efficiency development. Among the frame range of interaction by 3 persons, physiology state and attribution are regarded as the personal cognition and factor: the direct master on experience is regarded as behavior engaged by individual, vicarious experience (behavior model of other persons), oral persuasion (other people) and other clues (such as task, resources and other situational factors) are regarded as environment influence, all of these can affect personal computer self-efficiency development.

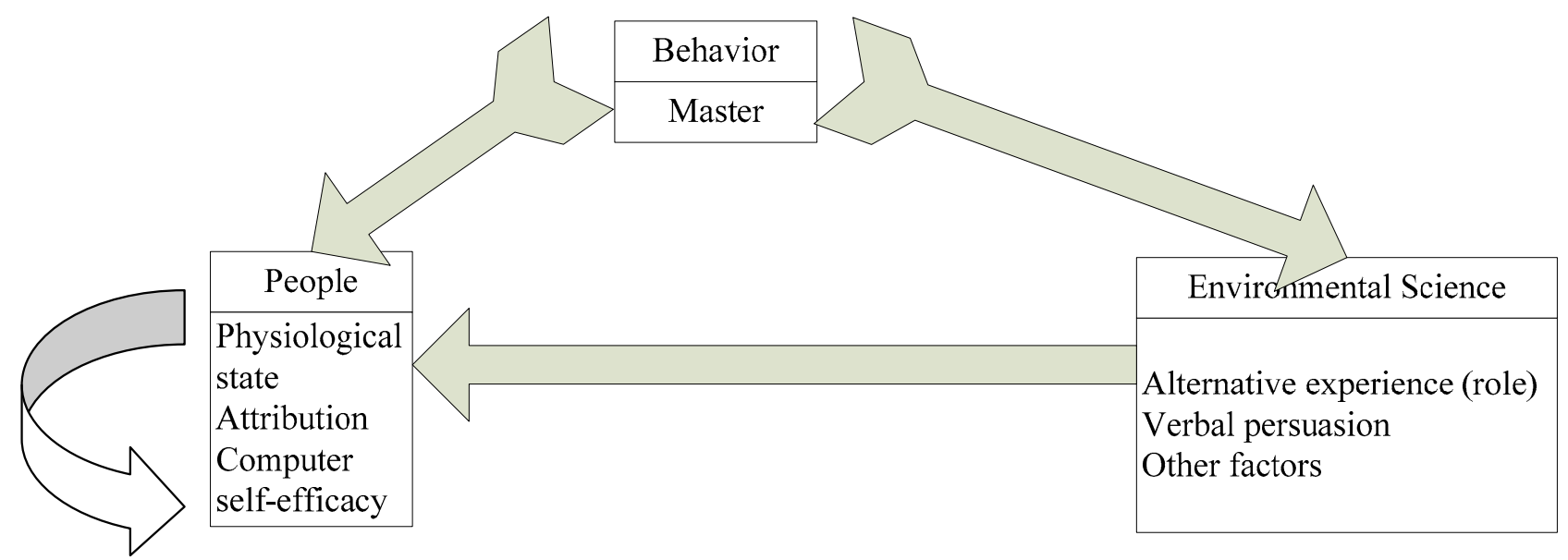

Diagram 1 Influence factors of computer self-efficiency

Computer self-efficiency sense can be divided into 3 dimensions: magnitude, strength and generalizability. Among the interaction frame by 3 persons, computer self-efficiency affects individual cognition and emotion, this includes sense effectiveness, usability and anxiety. Computer self-efficiency can also be regarded as behavior affecting individual, including behavior choice (behavior intention), performance and effort (persistence).

If the target of one person is behavior prediction but not behavior comprehension or behavior effect, so it is reasonable to delete computer self-efficiency, that is to say of target is to predict who will use computer, measure the prior state, such as intention and sensible effectiveness etc are most effective. However, if target is one kind of development way of behavior and its cause, or target is to implement effect on future behavior, so it is very important to understand role of computer self-efficiency. As it is indicated by diagram 2, it demonstrates anxiety is closely related to computer self-efficiency, the developed special computer self-efficiency level has close relations to the anxiety 
exists in the whole performance process. It thinks that emotional arousal is the key cause for existence of self-efficiency sense, performance spiral; the spiral can be changed into prediction through mechanism like self-efficiency and anxiety.

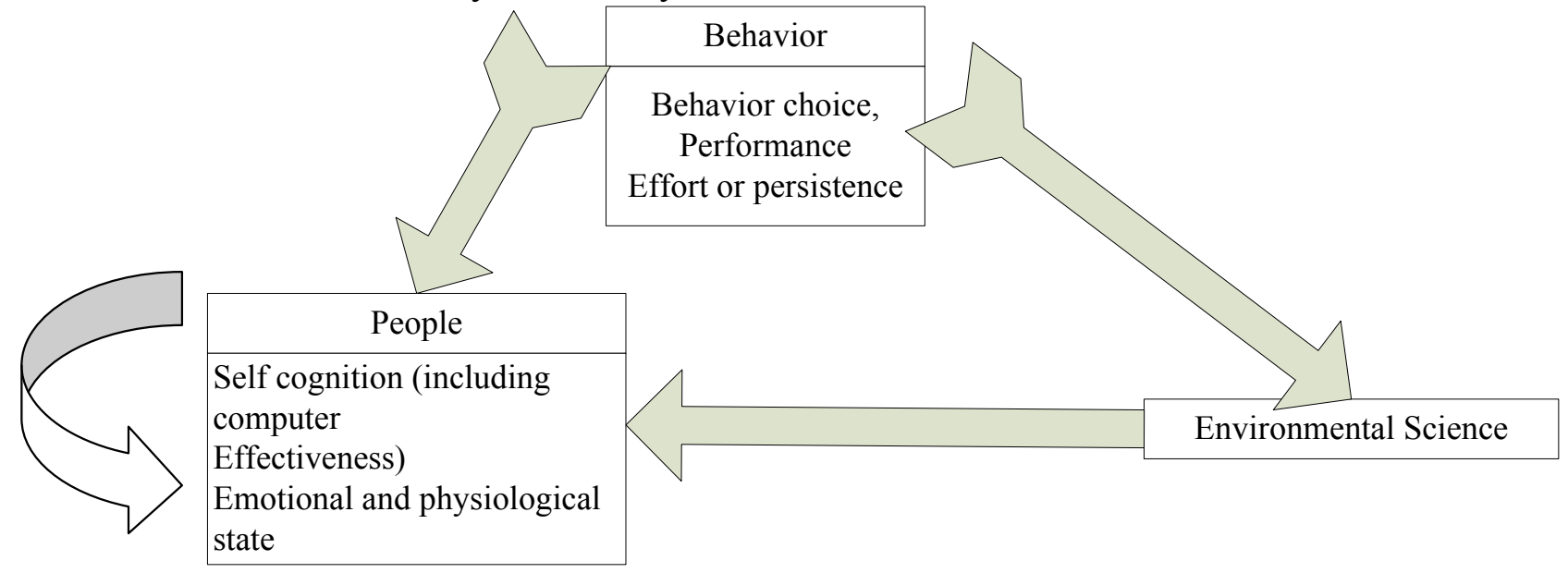

\section{Enhancement of computer self-efficiency}

Diagram 2 Computer self-efficiency

Through application on computer by us, such as formal training, self-learning, introduction of new technology and daily usage, it has enhancement of different degree on ability and confidence in computer application. In this environment, people develop their ability and confidence; they are interested in internet of influence factor to identify self-efficiency development of driving computer. The formal training is primary; it is also the most obvious development environment for compute self-efficiency. As it is indicated by diagram 3, attribution, target orientation and self-adjustment are regarded as the individual cognition factor of affecting computer self-efficiency. Problem solution and self-learning activity are regarded as the behavior of affecting computer self-efficiency, while learning and reception and performance are regarded as behavior affected by computer self-efficiency. Environmental influence includes formal training and pre-post training support provided to individual.

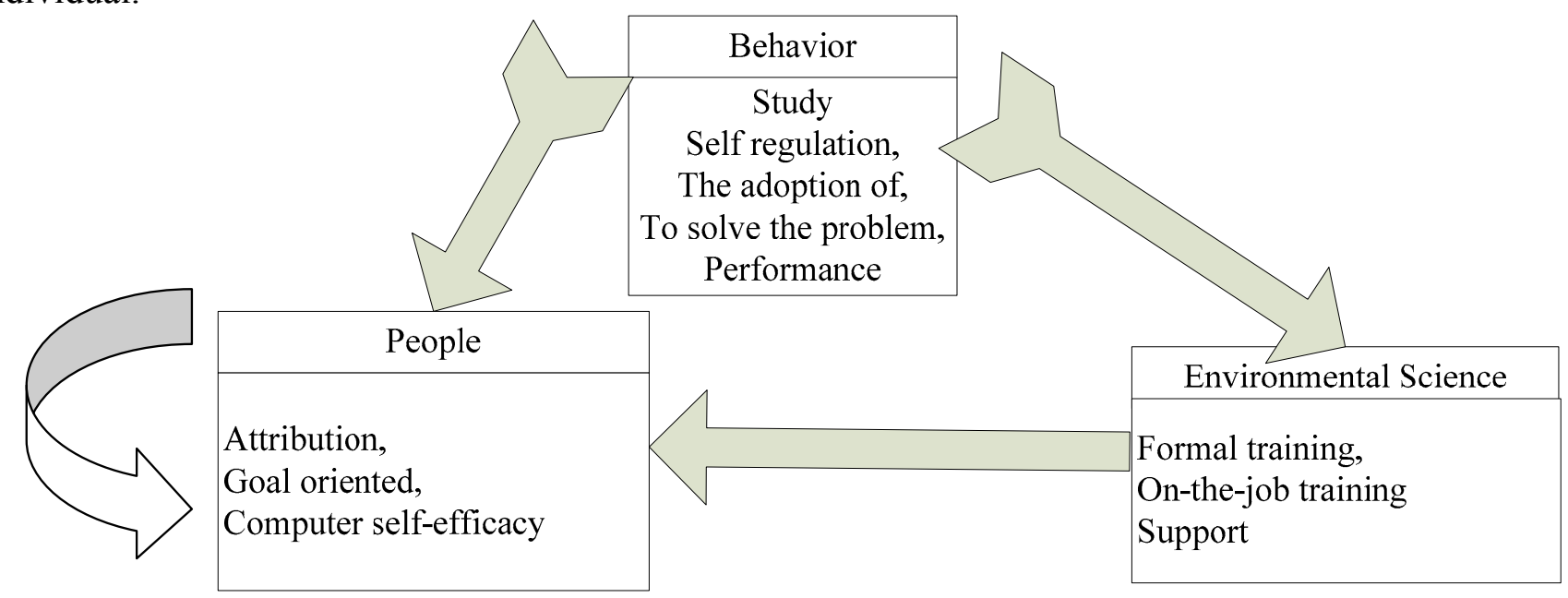

Diagram 3 Enhancement of computer self-efficiency

\section{Research design and method on information technology and college English integration}

\section{Research design}

This research uses the full-time teachers in foreign language education institute of Liaocheng University as investigation objects, in the whole research process, very teacher has one code and anonym to represent them, it uses P2501-P2520 as code of 20 teachers, 25 is the number of institute given by college. While the anonym of teachers use English names chosen by them. This research is based on methods such as investigation, interview, observation and class design and division to make 
research. In this research, it uses tools made by Albion (2001) and Mills (2003) to make data collection, and it makes adaptation according to real condition of college English class. The statistics result uses SPSS software to make data analysis, the obvious level is set less than 01. It makes analysis on main application component analysis, Kaiser Standard and reaction of Varimax rotation to matching. Kaiser standard is used to determine to keep which component, Varimax rotation is used to detect factor load. The result indicates that, computer technology self-efficiency and grade obtained in the given basic computer technology training unit presents obvious correlation; this may be enhance confidence in using computer. In order to better make investigation on objects of this research, information technology self-efficiency of college English teachers, it makes improvement on self-efficiency belief scale. Before test, it makes credibility and effectiveness test on self-efficiency scale. It uses coherent parameter on effectiveness of this scale (the same credibility, it is also regarded as Cronbach alpha parameter), as it is indicated by table 1, from the table we can see that, attitude and belief, word procession, e-mail, PPT, electronic table, data base, operation system and file management, every dimension of network and the overall Cronbacha parameters are respectively $0.875,0.892,0.769,0.876,0.845,0.858,0.821,0.835,0.927$, the coherent parameter within the major scale is 0.927 , the coherence parameter of every dimension is between 0.769 and 0.892 . It belongs to the reliable range and the corresponding combination reliability is respectively $0.87,0.89,0.79,0.88,0.85,0.86,0.82,0.83,0.95$, all are bigger than 0.5 , so it meets reliability requirement.

Table 1 Reliability analysis result on computer self-efficiency scale of teachers

\begin{tabular}{llllllllll}
\hline Variable & $\begin{array}{l}\text { attitude } \\
\text { and } \\
\text { belief }\end{array}$ & $\begin{array}{l}\text { Word } \\
\text { processioin }\end{array}$ & e-mail & PPT & $\begin{array}{l}\text { Electronic } \\
\text { table }\end{array}$ & $\begin{array}{l}\text { Data } \\
\text { base }\end{array}$ & $\begin{array}{l}\text { operaton } \\
\text { system and } \\
\text { file } \\
\text { management }\end{array}$ & network & $\begin{array}{l}\text { Total } \\
\text { scale }\end{array}$ \\
\hline $\begin{array}{l}\text { Cronbach } \\
\begin{array}{l}\text { Alpha( } \alpha) \\
\text { parameter }\end{array}\end{array}$ & 0.875 & 0.892 & 0.769 & 0.876 & 0.845 & 0.858 & 0.821 & 0.835 & 0.927 \\
$\begin{array}{l}\text { Combination } \\
\text { relaibility }\end{array}$ & 0.87 & 0.89 & 0.79 & 0.88 & 0.84 & 0.86 & 0.82 & 0.83 & 0.95 \\
\hline
\end{tabular}

In this research, it uses factor analysis method to make demonstration on structure validity of computer self-efficiency. Through demonstration, the factor load of computer self-efficiency varies from 0.587 to 0.796 , which is far higher than the acceptable value of 0.30 ; from this we can see that scale has better structure validity. If want to determine the integration degree on information technology integration in English teacher teaching practice of college, we use 2 tools. The second tool is technology integration self-assuagement tool (Mills, 2000). It uses TISA to represent it in the paper.

\section{Data resources and research plan}

In the invitation e-mail has been sent, there are 25 teachers reply they are willing to participate in this research, while afterwards, there are 20 teachers provide self-assessment investigation table in the regulated time. Every participant will produce 125 data on reply to self-assessment. It uses descriptive statistics, parameter and non-parameter test, variance analysis to make analysis.

The collected information includes age, teaching experience (year), received profession development time related to technology of English teachers in college. These data are regarded as component of CSE and TISA. Research and design adopt multiple strategies to test whether they can obtain the similar result and discovery. Except for this, the data level can also provide profound comprehension. Data of the first level from this research is about information of population census, including name of participant, the grade they taught. The next level includes the site note under detailed condition, then the third level includes recorded interview. The last level includes conclusion based on summary and deduction, it is used as the result of testing statistics result and measurement data. 


\section{Research result of college English and information technology integration}

\section{Result of demonstration research}

Participant uses descriptive statistics, parameter and non-parameter test and variance analysis to make analysis on reply of computer self-efficiency scale and information technology integration. The collected data is directly input into SPSS to make data statistics and analysis. There are 25 voluntary participants, and in the end there are 10 teachers complete the questionnaire. The characteristics of participants include the total marks of participants, the grade they teach, teaching experience (year), as well as assessed week number of profession development. Computer self-efficiency is divided into 8 dimensions (one attitude and 7 technology dimensions), it develops investigation on these dimensions, and the main cause is to determine whether to make classified analysis on them or not. In table 3, participants reply to the former 45 detailed indexes before investigation tools, these descriptions indicate that universal attitude of participants on computer application. The value is represented by 1-4 in Richert scale, of which 4 represents most agree, while 1 represents most disagree. In order to determine whether information technology integration self-assessment of teachers has relations to computer self-efficiency or not, it needs to calculate the average marks of participants in these 2 tools, it is indicated by diagram 2 . The mark of computer self-efficiency needs to be summarized on the total marks of all the dimensions, and then divides the total number of problems (107). Test on self-assessment of average of technology integration varies from 0 to 15 , in order to make this variable of different kinds have comparability to continuation rate of computer self-efficiency, the self-assessment reaction average of every information technology divides 4, so it produces the result in table 2 , the data is accurate to two digits after decimal.

Table 2 The average value of computer self-efficiency and technology integration

\begin{tabular}{ccc}
\hline Partiicpant code & average valye of computer self-efficiency & $\begin{array}{c}\text { Self-assessment average value } \\
\text { of technology integration }\end{array}$ \\
\hline P2501 & 3.95 & 3.08 \\
P2502 & 3.90 & 2.58 \\
P2503 & 3.92 & 3.38 \\
P2504 & 3.86 & 2.99 \\
P2505 & 3.45 & 1.48 \\
P2506 & 3.75 & 1.76 \\
P2507 & 3.02 & 1.61 \\
P2508 & 3.31 & 2.11 \\
P2509 & 2.74 & 2.26 \\
P2510 & 3.69 & 2.49 \\
\hline
\end{tabular}

In order to determine whether computer has stronger correlation in certain detailed dimension on self-efficiency, the measurement result of computer self-efficiency divides on certain detailed dimensions, on calculating total marks in certain dimension and then divides the problem quantity in this dimension, it is indicated by diagram 3 .

After testing the average value, it needs to use plenty of statistics procedures to seek relations between independent variable and dependent variable. The pillar statistics diagram produced by dimension statistics of computer self-efficiency and technology integration indicates that they present abnormal distribution. In the tool of computer self-efficiency, among 8 different dimensions, there are plenty of changes; coupling with that response to technology integration self-efficiency is diversified. Therefore, it is a big problem whether it can use parameter and non-parameter to analyze their relations. Parameter analysis is implemented under condition that sample data conforms to normal distribution, while non-parameter analysis is the opposite. Meanwhile, because sample is relatively smaller $(n=20)$, and the participants are chosen from among 30 teachers they are supposed to present normal distribution, therefore, parameter test can be used to make conclusion on average value. 
Table 3 Average value pf CSE dimension and TISA

\begin{tabular}{llllllllll}
\hline $\begin{array}{l}\text { participant } \\
\text { code }\end{array}$ & $\begin{array}{l}\text { CSE } \\
\text { attitude }\end{array}$ & $\begin{array}{l}\text { CSE word } \\
\text { procession }\end{array}$ & $\begin{array}{l}\text { CSE } \\
\text { e-mail }\end{array}$ & CSEPPT & $\begin{array}{l}\text { CSE } \\
\text { electronic } \\
\text { table }\end{array}$ & $\begin{array}{l}\text { CSE } \\
\text { data } \\
\text { base }\end{array}$ & $\begin{array}{l}\text { CSE } \\
\text { operation } \\
\text { system and } \\
\text { file } \\
\text { management }\end{array}$ & $\begin{array}{l}\text { CSE } \\
\text { network }\end{array}$ & $\begin{array}{l}\text { CSE } \\
\text { total } \\
\text { scale }\end{array}$ \\
\hline P2501 & 3.8 & 4.0 & 4.0 & 3.9 & 4.0 & 3.9 & 4.0 & 4.0 & 3.08 \\
P2502 & 4.0 & 4.0 & 4.0 & 3.8 & 4.0 & 3.4 & 4.0 & 4.0 & 2.58 \\
P2503 & 3.9 & 4.0 & 4.0 & 3.8 & 4.0 & 3.7 & 4.0 & 4.0 & 3.38 \\
P2504 & 3.9 & 4.0 & 4.0 & 3.9 & 4.0 & 3.1 & 4.0 & 4.0 & 2.99 \\
P2505 & 3.5 & 4.0 & 4.0 & 2.9 & 3.3 & 3.4 & 3.6 & 3.7 & 1.48 \\
P2506 & 3.8 & 4.0 & 4.0 & 3.1 & 4.0 & 3.3 & 3.9 & 3.9 & 1.76 \\
P2507 & 3.3 & 4.0 & 4.0 & 2.3 & 2.7 & 2.0 & 3.0 & 2.9 & 1.61 \\
P2508 & 3.7 & 4.0 & 4.0 & 3.0 & 4.0 & 3.2 & 2.9 & 3.7 & 2.11 \\
P2509 & 3.4 & 4.0 & 4.0 & 3.1 & 4.0 & 3.4 & .0 & .0 & 2.26 \\
P2510 & 3.7 & 4.0 & 4.0 & 3.3 & 3.7 & 2.8 & 4.0 & 4.0 & 2.49 \\
\hline
\end{tabular}

Result on correlation research is in table 4 , the obtained Pearson correlation coefficient value is 0.567 or $\mathrm{r}=0.6$, in the two-tailed test, the obvious difference value is 0.05 . Because Pearson correlation coefficient value varies from the weakest.00 to the strongest 1.00 , so, when obvious difference values reaches 0.05 , Pearson correlation coefficient value $r=0.6$ can provide evidence of medium degree. In the sample it calculates mark of self-efficiency has correlation to technology integration self-assessment. Therefore, zero assumption is eliminated.

Table 4 The correlation between average mark of computer self-efficiency and average mark of technology integration

\begin{tabular}{|l|l|l|l|}
\hline & & Average mark of TISA & Average mark of CSE \\
\hline Average mark of TISA & Pearson correlation & 1 & .567 \\
\hline & $\begin{array}{l}\text { significance } \\
\text { (two-tailed })\end{array}$ & .020 & \\
\hline & $\mathrm{n}$ & 20 & 20 \\
\hline Average mark of CSE & Pearson correlation & $.567^{*}$ & 1 \\
\hline & $\begin{array}{l}\text { significance } \\
\text { (two-tailed })\end{array}$ & .020 & 20 \\
\hline & $\mathrm{n}$ & 20 & 2 \\
\hline
\end{tabular}

In the diagram 15 of related matrix, the matrix is used to determine the relations between latitude of computer self-efficiency and technology integration self-assessment. Just as it is indicated by diagram, their relations varies from the operation system with the lowest correlation parameter $(r=1)$ to data base latitude with the highest latitude $(\mathrm{r}=6)$ of file management.

Table 5 Related matrix on each latitude of technology integration self-assessment and computer self-efficiency

\begin{tabular}{|c|l|l|l|l|l|l|l|}
\hline & $\begin{array}{l}\text { CSE } \\
\text { attitude }\end{array}$ & $\begin{array}{l}\text { CSE word } \\
\text { procession }\end{array}$ & PPT & $\begin{array}{l}\text { CSE } \\
\text { electronic } \\
\text { table }\end{array}$ & $\begin{array}{l}\text { CSE data } \\
\text { base }\end{array}$ & $\begin{array}{l}\text { CSE file } \\
\text { management }\end{array}$ & $\begin{array}{l}\text { CSE } \\
\text { network }\end{array}$ \\
\hline $\begin{array}{c}\text { TISA scale } \\
\text { Pearson } \\
\text { correlation }\end{array}$ & $0.557\left(^{*}\right)$ & 0.358 & 0.423 & $0.529(*)$ & $0.634(* *)$ & 0.139 & 0.245 \\
\hline $\begin{array}{c}\text { significance } \\
\text { (two-tailed })\end{array}$ & 0.011 & 0.115 & 0.383 & 0.025 & 0.007 & 0.532 & 0.369 \\
\hline $\mathrm{n}=20$ & & & & & & & \\
\hline
\end{tabular}

- Related parameter is obvious(two-tailed) in obvious level of 0.05

** Related parameter is obvious (two-tailed) in obvious level of 0.01 


\section{Self-improvement mechanism}

Computer self-efficiency of English teachers in college has important effect on integration of information technology and course in their teaching practice, so the most effective methods of enhancing technology integration by teachers is to enhance their computer self-efficiency. It can be realized by the following channels:

(1) It can reduce their application anxiety by enriching computer knowledge and experience of teachers, so that it can enhance their computer self-efficiency. Therefore, in the profession development of teachers, teaching content should properly increase computer knowledge and usage experience of computer in the cognition field. Especially for those teachers with lower computer level, increasing their computer experience is the most direct and effective method to reduce their computer anxiety, therefore, we should provide more opportunities for them to use computer and give them proper instruction; increase their computer experience, so that increase their computer self-efficiency.

(2) When teachers feeling that they can control computer software used by them, their computer anxiety will be effectively reduced. While the acquisition of this control sense is closely related to design of computer software. Therefore, computer software(college English software) developers can make users clearly realize the position of them by providing navigation system with better functions, in addition, it can adopts ways with compact structuring to complete design of computer software, this teachers can conveniently complete their own tasks according to strict steps provided by system. In the end, the help system with complete content can also increase control sense of college English teachers on computer.

(3) In the process of English teaching by teachers, they can certainly achieve ideal result and gradually establish their confidence by their efforts when facing with technology difficulty, they can realize their efforts are effective in every small progress, so that they can gradually enhance their computer self-efficiency.

(4) They should properly arrange certain practice experience and make teachers experience the first-hand practice experience, this they can timely find the content have not been mastered by them, and finally increase their computer self-efficiency through instructor or consultation from the same industry.

\section{Summary}

With the approaching in teaching reform of college English teaching, researchers pay increasingly high attention to teachers. Class internet environment of college English is the material and spirit guarantee for ecosystem balance of class. This paper chooses the micro topic on computer self-efficiency of teachers on this basis, it hopes to discuss relations between belief level held by teachers and information technology integration by teachers through investigation on computer self-efficiency of English teachers in college, providing one new perspective and breakthrough point on teacher investigation, hoping to make contributions to teacher development and English teaching reform of college.

\section{References}

[1] Angeli C, Valanides N. Epistemological and methodological issues for the conceptualization, development, and assessment of ICT-TPCK: Advances in technological pedagogical content knowledge (TPCK). Computers \& Education, Vol1, 2009, 52, p 154-168.

[2] He Kekang. TPACK. Channel and Method Research New Development Information Technology and Course Integration in America(II). Audio-Visual Education Research. Vol 6,2012, p47-56..

[3] Zhan Yi, Ren Youqun. The Connotation of Subject Teaching Method Knowledge of Integration Technology and Its State Overview. Remote Education Magazine, Vol 4,2010, p78-79.

[4]Ren Youqun,Zhan Yi. Subject Teaching Knowledge of Integration Technology: Educators Brochure. Beijing: Educational Science Publishing Press, 2011, p123-124. 
[5] Xu Peng, Wang Yining, Zhang Hai, Liu Yanhua. Research State in Abroad on TPACK Measurement Method and Illumination. Audio-Visual Education Research , Vol 12,2013,p98-101.

[6] Li Meifeng, Li Yi. TPCK: New Frame on Teacher professional Knowledge of Integration Technology. Higher Education Research of Heilongjiang, Vol 4, 2008, p74-77.

[7] Chen Jing. Education Technology and Ability Cultivation of Teachers under the Perspective of STPACK of Integration Technology. Audio-Visual Education Research, Vol 6, 2009, p29-32.

[8] He Kekang. Information Technology and Course and Course Integration Theory of Profound Level. Beijing Normal University Press, 2008, p11-14. 